\title{
Fulminant Pneumonia Caused by Nontypable Haemophilus Influenzae
}

\begin{abstract}
Kiyoharu Fukushima ${ }^{1}$, Hiroshi Doi $^{2}$, Shigeto Hamaguchi ${ }^{3}$ and Kazunori Tomono ${ }^{3}$
Key words: Haemophilus influenzae, sepsis, pneumonia, type b, nontypable

(Intern Med 52: 1755, 2013)

(DOI: 10.2169/internalmedicine.52.0297)

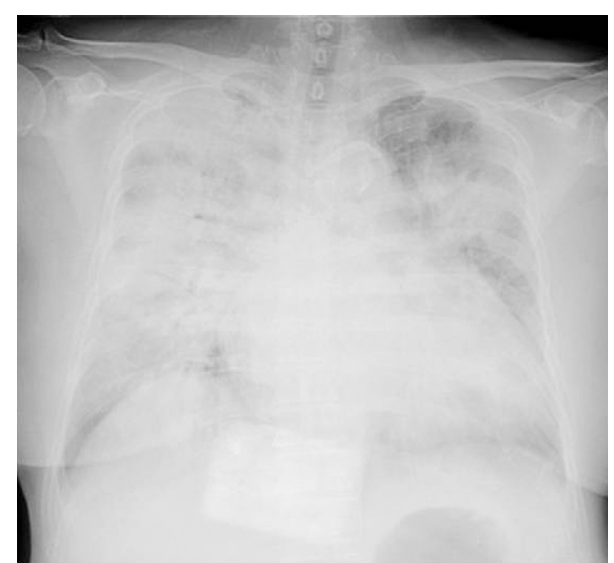

Picture.

spectrum antibiotics were immediately administered. Despite receiving intensive care, the patient died the next day. Haemophilus influenzae was later isolated in both the sputum sample and two sets of blood cultures that were obtained upon admission. The serotype of the strain that was obtained from the blood culture was identified using a Denka Seiken Agglutinating Sera kit, an H. influenzae type a-f kit (Denka Seiken Co., Ltd., Tokyo, Japan) and an $H$. influenzaespecific bexA, bexB and pepN polymerase chain reaction (1). The strain was subsequently confirmed to be nontypable $H$. influenzae. Clinicians should therefore be aware of this fatal infection in this era of $H$. influenzae type $b$ conjugate vaccines (2).
\end{abstract}

A 75-year-old previously healthy woman was transferred to our hospital with acute onset dyspnea. Chest radiography revealed the presence of diffuse bilateral infiltrates (Picture), and the laboratory data revealed signs of acute inflammation (white blood cell count: 4,000 cells/mL, C-reactive protein: $13.8 \mathrm{mg} / \mathrm{dL}$ and procalcitonin: $3.44 \mathrm{ng} / \mathrm{mL}$ ). She was therefore intubated for severe respiratory failure, and broad-
The authors state that they have no Conflict of Interest (COI).

\section{References}

1. Davis GS, Sandstedt SA, Patel M, Marrs CF, Gilsdorf JR. Use of bexB to detect the capsule locus in Haemophilus influenzae. J Clin Microbiol 49: 2594-2601, 2011.

2. Agrawal A, Murphy TF. Haemophilus influenzae infections in the H. influenzae type b conjugate vaccine era. J Clin Microbiol 49: 3728-3732, 2011.

\footnotetext{
${ }^{1}$ Department of General Internal Medicine, Kanagawa Prefectural Ashigara-kami Hospital, Japan, ${ }^{2}$ Department of Cardiology, Kanagawa Prefectural Ashigara-kami Hospital, Japan and ${ }^{3}$ Division of Infection Control and Prevention, Osaka University Hospital, Japan Received for publication February 7, 2013; Accepted for publication April 8, 2013

Correspondence to Dr. Kiyoharu Fukushima, kiyoharufukushima@hotmail.co.jp

(C) 2013 The Japanese Society of Internal Medicine Journal Website: http://www.naika.or.jp/imonline/index.html
} 